\title{
Subdural Empyema by Enterobacter cloacae: Case Report
}

\author{
Fernando Celi ${ }^{1}$ Giancarlo Saal-Zapata ${ }^{2, \odot}$ \\ ${ }^{1}$ Department of Neurosurgery, Hospital de Emergencias José \\ Casimiro Ulloa, Miraflores, Lima, Perú \\ 2Department of Neurosurgery, Hospital Nacional Guillermo \\ Almenara Irigoyen - EsSalud, La Victoria, Lima, Perú \\ Indian J Neurotrauma:2021;18:72-74
}

\begin{abstract}
Address for correspondence Giancarlo Saal-Zapata, MD, Grau Avenue 800, La Victoria, Lima 13, Perú (e-mail: gian_carlo1987@hotmail.com, gsaal1987@gmail.com).
\end{abstract}

\section{Abstract \\ Keywords \\ - subdural empyema \\ - chronic subdural hematoma \\ - Enterobacter cloacae}

Infections of the central nervous system are a medical emergency, potentially lethal and associated with increased morbidity and mortality. We present the case of a male with risk factors and clinical deterioration, in which the brain computed tomography scan showed a subdural collection following a head injury, which underwent surgical evacuation revealing a subdural empyema. The culture of the subdural collection yielded a positive result to Enterobacter cloacae.

\section{Introduction}

Infections of the central nervous system include meningitis, ventriculitis, empyema, and abscesses that can manifest with fever, vomiting, clinical deterioration, hydrocephalus, brain edema, and seizures requiring medical and surgical treatment to avoid complications. ${ }^{1}$

The diagnosis and treatment of a subdural empyema are sometimes difficult due to the similar radiological characteristics to chronic subdural hematomas, and the treatment includes the evacuation of the collection associated with intravenous antibiotics. ${ }^{2}$

Herein, we present the case of a patient with risk factors who developed a subdural empyema that was treated by surgical and medical means.

\section{Case Description}

A 38-year-old male patient with a past medical history of drug consumption and a traumatic brain injury 1 week prior to admission was referred to the emergency department with decreased level of consciousness, seizures, and fever. At admission, the vital signs were: temperature: $38.9^{\circ} \mathrm{C}$, a heart rate of 96 beats/min, and blood pressure of 103/66 mm Hg. Neurological examination revealed Glassgow coma scale (GCS) (O2V3M5 = 10), left-sided hemiparesis, and anisocoria. Neuroimaging studies revealed a subdural collection compatible with a subacute subdural hematoma in the right hemisphere and associated midline shift and a skull fracture ( - Fig. 1). The decision to evacuate the collection was made. A right-sided craniotomy was performed, the dura was opened, and a thick membrane was found, which was resected, and a purulent subdural collection was evacuated; these findings were compatible with a subdural empyema. A subdural drainage with continuous irrigation was placed and empiric intravenous antibiotics were initiated. In the immediate postoperative course, symptoms improved and the computed tomography (CT) scan showed a partial evacuation of the empyema with a residual collection and midline shift (-Fig. 2). The subdural drain was removed. Two days after the procedure, the patient presented fever and lethargy. Analytics showed a white blood cell count of $14500 \times 10^{3} / \mathrm{mm}$, accelerate erythrocyte sedimentation rate $(65 \mathrm{~mm} / \mathrm{h})$, elevated C-reactive protein $(182 \mathrm{mg} / \mathrm{L})$, and an increase in segmented neutrophils (81\%). A new CT scan revealed a right subdural collection with midline shift ( $\sim$ Fig. 3). The patient underwent an emergent right decompressive craniectomy and a yellowish purulent material with residual capsule and thick pus attached to the pia mater membrane were found. The empyema cavity was irrigated with sterile saline solution until the returning fluid was clear ( - Fig. 4). The brain was noted to be swollen after pus evacuation. Postoperatively, the patient was transferred to the intensive care unit with slowly favorable recovery with empiric intravenous antibiotic therapy. A bacterial culture of the purulent specimen identified Enterobacter cloacae and a specific antibiotic regimen was initiated. published online

October 9, 2020
DoI https://doi.org/

10.1055/s-0040-1718782 ISSN 0973-0508.
C2020. Neurotrauma Society of India.

This is an open access article published by Thieme under the terms of the Creative Commons Attribution-NonDerivative-NonCommercial-License, permitting copying and reproduction so long as the original work is given appropriate credit. Contents may not be used for commercial purposes, or adapted, remixed, transformed or built upon. (https://creativecommons.org/licenses/by-nc-nd/4.0/).

Thieme Medical and Scientific Publishers Pvt. Ltd. A-12, 2nd Floor, Sector 2, Noida-201301 UP, India 


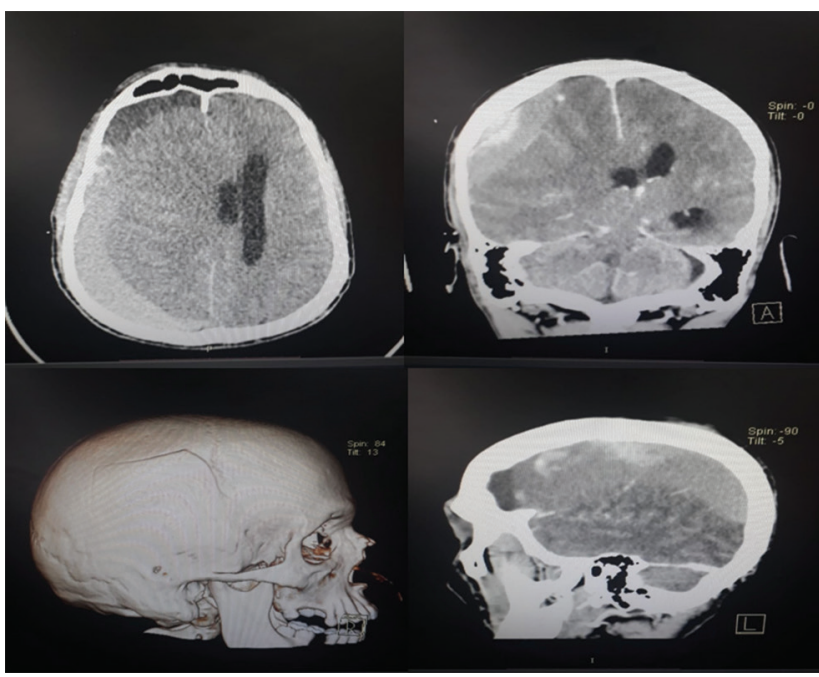

Fig. 1 Brain computed tomography scan showing a subdural collection with hypodense and hyperdense lesions with midline shift and skull fracture.

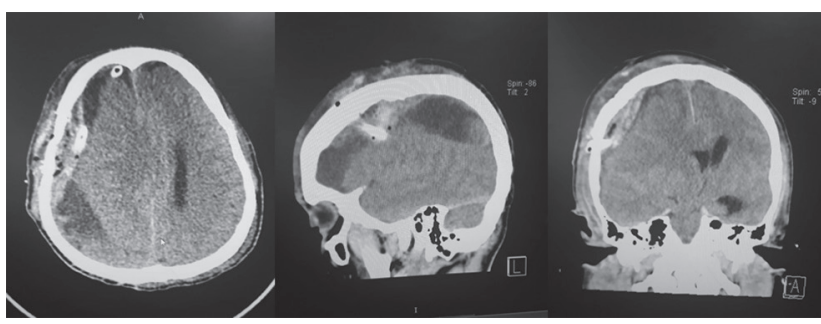

Fig. 2 Postoperative computed tomography scan showing evacuation of empyema with the presence of a subdural drainage and midline shift.

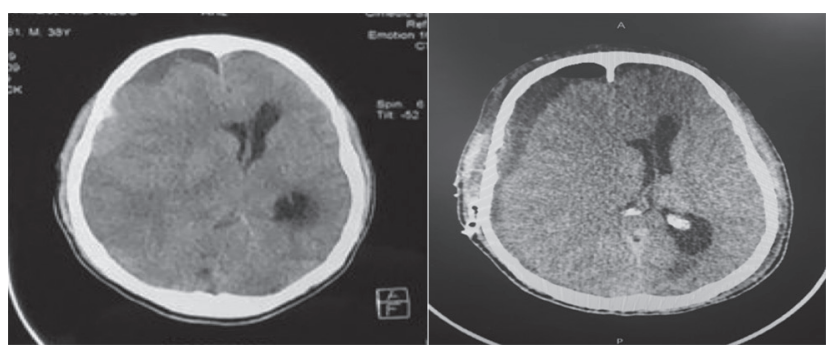

Fig. 3 Computed tomography scan with right subdural collection and midline shift despite the craniotomy and drainage.

\section{Discussion}

Subdural empyema is a surgical emergency associated with high mortality and constitutes 15 to $25 \%$ of pyogenic intracranial infections, more commonly in men., This entity can be difficult to diagnose because of its nonspecific presentation. ${ }^{5,6}$ Overall, this patient could present alterations of consciousness, seizures, meningeal irritation, and nonspecific symptoms such as fever, headache, and purulent rhinorrhea. ${ }^{7.8}$

The treatment of a subdural empyema consists of three points: surgical evacuation of pus, eradication of the primary foci of infection, and adequate antibiotic therapy. Craniectomy plus evacuation of the empyema and fibrinoid material were performed in this patient (it ensures maximal

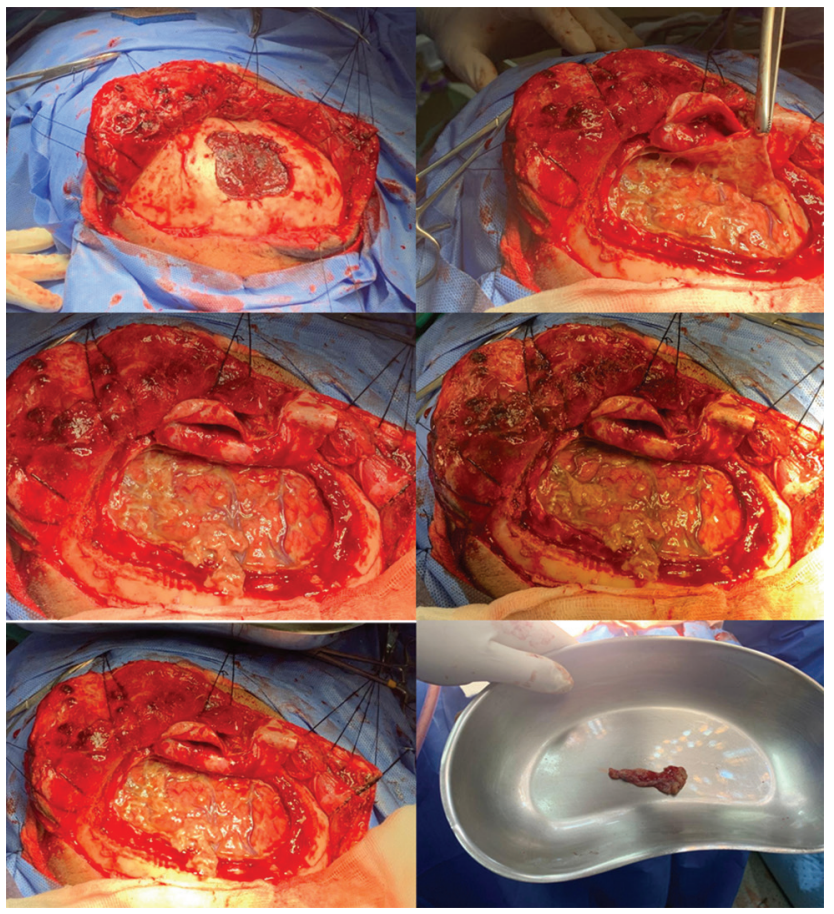

Fig. 4 Intraoperative images of the empyema capsule and purulent content. A yellowish purulent material with residual capsule and thick pus attached to the pia mater membrane.

drainage of the loculated pus and allows the total removal of the infected hematoma capsule). Our patient developed a lesion with considerable mass effect with a well-defined capsule confirmed by the craniectomy. ${ }^{3,9}$

The culture of this patient was positive for Enterobacter cloacae which are facultative anaerobic gram-negative strains belonging to the family of Enterobacteriaceae and are widely found in nature. ${ }^{10,11}$ These microorganisms are saprophytic in the environment, as they are found in soil and sewage, and are also part of the commensal enteric flora of the human gastrointestinal tract. ${ }^{10,11}$

Enterobacter cloacae is an important nosocomial pathogen responsible for bacteremia and lower respiratory tract, urinary tract and intra-abdominal infections, as well as endocarditis, septic arthritis, osteomyelitis, and skin and soft tissue infections. The skin and the gastrointestinal tract are the most common sites through which Enterobacter cloacae can be contracted. ${ }^{12,13}$

Our patient had a history of drug addiction; this point was a contributing factor for the disease. The pathology in this patient could be the result of secondary infection of a chronic subdural hematoma or hygroma following a traumatic brain injury. ${ }^{9}$ The presence of a skull fracture as a mark of head injury in this particular case was a major predisposing factor for the development of a subdural collection.

Neurological symptoms such as mental status alteration and seizures, as well as fever and anisocoria were unspecific symptoms of empyema., ${ }^{2,14}$ On plain CT imaging, a subdural empyema resembles a subdural hematoma in its crescent shape. In this case, the CT images mimicked a chronic subdural hematoma. ${ }^{15-17}$ Despite the first surgery achieved the evacuation of the empyema, a worsening of the tomographic 
findings and clinical status were appreciated 2 days after the procedure.

Many causes of subdural empyema have been reported: otitis media, mastoiditis, and sinusitis were the most frequent primary foci. ${ }^{1}{ }^{18}$ Other causes are postcranial surgery and brain traumatic injury with an associated skull fracture.

Subdural empyema is difficult to diagnose because of its unspecific presentation and imaging; the neurosurgical management and antibiotic therapy are keys to decrease the morbidity and mortality.

\section{Conclusion}

Subdural empyema is a rare but devastating condition that causes a high mortality and disability. The diagnosis and treatment should be suspected to evacuate the lesion and start intravenous antibiotic therapy, which will improve the long-term results and mortality.

\section{Funding \\ None. \\ Conflict of Interest \\ None declared.}

\section{References}

1 Widdrington JD, Bond $\mathrm{H}$, Schwab $\mathrm{U}$, et al. Pyogenic brain abscess and subdural empyema: presentation, management, and factors predicting outcome. Infection 2018;46(6):785-792

2 Doan N, Patel M, Nguyen HS, et al. Intracranial subdural empyema mimicking a recurrent chronic subdural hematoma. J Surg Case Rep 2016;2016(9):rjw158

3 Kim Y-S, Joo S-P, Song D-J, Kim S-H, Kim T-S. Delayed intracranial subdural empyema following burr hole drainage: case series and literature review. Medicine (Baltimore) 2018;97(18):e0664-e0664

4 Holland AA, Morriss M, Glasier PC, Stavinoha PL. Complicated subdural empyema in an adolescent. Arch Clin Neuropsychol 2013;28(1):81-91
5 Alimehmeti R, Seferi A, Stroni G, et al. Burr hole evacuation for infratentorial subdural empyema. World J Clin Cases 2013;1(5):172-175

6 Munusamy T, Dinesh SK. Delayed occurrence of Escherichia coli subdural empyema following head injury in an elderly patient: a case report and literature review. J Neurol Surg Rep 2015;76(1):e79-e82

7 Shen Y-Y, Cheng Z-J, Chai J-Y, et al. Interhemispheric subdural empyema secondary to sinusitis in an adolescent girl. Chin Med J (Engl) 2018;131(24):2989-2990

8 Kural C, Kırmızıgoz S, Ezgu MC, Bedir O, Kutlay M, Izci Y. Intracranial infections: lessons learned from 52 surgically treated cases. Neurosurg Focus 2019;47(2):E10

9 Konar S, Gohil D, Shukla D, et al. Predictors of outcome of subdural empyema in children. Neurosurg Focus 2019;47(2):E17

10 Mezzatesta ML, Gona F, Stefani S. Enterobacter cloacae complex: clinical impact and emerging antibiotic resistance. Future Microbiol 2012;7(7):887-902

11 Davin-Regli A, Pagès J-M. Enterobacter aerogenes and Enterobacter cloacae; versatile bacterial pathogens confronting antibiotic treatment. Front Microbiol 2015;6:392

12 Dalben M, Varkulja G, Basso M, et al. Investigation of an outbreak of Enterobacter cloacae in a neonatal unit and review of the literature. J Hosp Infect 2008;70(1):7-14

13 Davin-Regli A, Lavigne J-P, Pagès J-M. Enterobacter spp.: update on taxonomy, clinical aspects, and emerging antimicrobial resistance. Clin Microbiol Rev 2019;32(4):e00002-e00019

14 French H, Schaefer N, Keijzers G, Barison D, Olson S. Intracranial subdural empyema: a 10-year case series. Ochsner J 2014;14(2):188-194

15 Aldinger FA, Shiban E, Gempt J, Meyer B, Kreutzer J, Krieg SM. Hollow screws: a diagnostic tool for intracranial empyema. Acta Neurochir (Wien) 2013;155(2):373-377

16 Gorman J, Randhawa N, Mendelsohn D, Honey CR, Heran MKS, Appel-Cresswell S. Subdural empyema. Can J Neurol Sci 2018;45(5):566-567

17 Neromyliotis E, Giakoumettis D, Drosos E, et al. Pediatric infratentorial subdural empyema: a case report. Surg Neurol Int 2018;9:104

18 Dabdoub CB, Adorno JO, Urbano J, Silveira EN, Orlandi BMM. Review of the management of infected subdural hematoma. World Neurosurg 2016;87:663.e1-663.e8 